\title{
High Performance Liquid Chromatographic Assay of Disaccharides and Oligosaccharides Produced by the Digestion of Glycosaminoglycans with Chondroitin Sulphate Lyases
}

\author{
By E. Gurr, G. Pallasch, S. Tunn, C. Tamm and A. Delbrück \\ Institut für Klinische Chemie II, Zentrum für Laboratoriumsmedizin der Medizinischen Hochschule Hannover, \\ Hannover
}

(Received May 9/September 28, 1984))

Summary: In high performance liquid chromatographic procedures hitherto described, $\mathrm{SiO}_{2}, \mathrm{NH}_{2}$ and $\mathrm{RP}$ columns have been used for the analysis of disaccharides produced by the digestion of glycosaminoglycans with the chondroitin sulphate lyases $\mathrm{AC}$ and $\mathrm{ABC}$. The use of a potent anion exchanger offers the following advantages over these columns: superior separation characteristics for non-sulphated disaccharides, and improved column performance, coupled with more stable analytical conditions. Elution with dilute saline solutions permits separation of the two non-sulphated disaccharides from chondroitin and hyaluronate.

The sequential application of chondroitinase $A C$ and $A B C$ permits the determination of hyaluronate, the chondroitin sulphate isomers and the dermatan sulphate isomers by high performance liquid chromatographic separation of the products of enzymatic hydrolysis. In a previously described method, hyaluronate lyase was used for the determination of hyaluronate. It has been found, however, that omission of the hyaluronate lyase step results in superior accuracy in the high performance liquid chromatographic separation of the nonsulphated disaccharides.

The enzymatic analysis of human articular cartilage glycosaminoglycans has repeatedly yielded a fraction which is not digestable by chondroitinase $\mathrm{AC}$, but is completely digestable by chondroitinase $\mathrm{ABC}$. More extensive characterization has disclosed that this fraction differs structurally from chondroitin sulphate. Enzymatic characterization indicates that it should presumably be assigned to dermatan sulphate.

Hochleistungsflüssigkeitschromatographische Bestimmung von Di- und Oligosacchariden aus dem Abbau von Glykosaminoglykanen mit Chondroitinsulfatlyasen

Zusammenfassung: Bei den bisher beschriebenen hochleistungsflüssigkeitschromatographischen Verfahren zur Analyse von Disacchariden aus dem Abbau von Glykosaminoglykanen mit den Chondroitinsulfatlyasen AC und $\mathrm{ABC}$ wurden $\mathrm{SiO}_{2-}, \mathrm{NH}_{2}-$ und $\mathrm{RP}-\mathrm{Säulen}$ verwendet. Gegenüber diesen Säulen bietet die Verwendung eines starken Anionenaustauschers folgende Vorteile: bessere Trenneigenschaften im Bereich der unsulfatierten Disaccharide und höhere Laufleistung pro Säulenfüllung bei stabileren Analysenbedingungen. Die Elution mit verdünnten Kochṣalzlösungen ermöglicht die Trennung der beiden unsulfatierten Disaccharide aus Chondroitin und Hyaluronat.

Durch die sequentielle Anwendung von Chondroitinase $\mathrm{AC}$ und $\mathrm{ABC}$ können durch hochleistungsflüssigkeitschromatographische Trennung der Metabolite Hyaluronat, die Chondroitinsulfatisomere sowie die Dermatansulfatisomere bestimmt werden. Verglichen mit einer früher beschriebenen Methode, bei der zur Hyaluronatbestimmung Hyaluronatlyase verwendet wurde, zeigt sich, daß ohne den Hyaluronatlyase-Schritt durch hochleistungsflüssigkeitschromatographische Trennung der unsulfatierten Disaccharide eine bessere Richtigkeit erreicht wird. 
Bei der enzymatischen Analyse von humanen Gelenkknorpelglykosaminoglykanen wurde immer eine Fraktion gefunden, die mit Chondroitinase $\mathrm{AC}$ nicht, mit Chondroitinase $\mathrm{ABC}$ aber vollständig abgebaut werden konnte. Eine weitergehende Charakterisierung zeigte, daß sie sich strukturell von Chondroitinsulfat unterschied. Aufgrund der enzymatischen Charakterisierung ist eine Zuordnung zum Dermantansulfat wahrscheinlich.

- 1

\section{Introduction}

The specific enzymes hyaluronate lyase, chondroitinase $\mathrm{AC}$ and chondroitinase $\mathrm{ABC}$ are being used increasingly for the determination of individual glycosaminoglycan components $(1-7)$. These enzymes digest hyaluronate, chondroitin sulphate and dermatan sulphate to form $\alpha$ - $\beta$-unsaturated uronic acids. Sequential application of these enzymes in the above order, and separation of the metabolites from the undigested glycosaminoglycans after each digestion step permits the determination of glycosaminoglycan distribution patterns. Quantification may then be performed by analysing the metabolites of the digested components (6) or by determining the concentrations of the undigested glycosaminoglycans $(5,7)$. Metabolite analysis is the preferred method because this also yields information on the degree of sulphation and the proportion of 4-sulphated and 6sulphated isomers.

Paper chromatography (8), thin-layer chromatography (9) and various high performance liquid chromatography methods $(10-15)$ have been described for the analysis of the $\alpha-\beta$-unsaturated uronic acids. Paper chromatography and thin-layer chromatography are time-consuming and relatively insensitive. High performance liquid chromatography should therefore be the method of choice by virtue of its speed and sensitivity.

One analytical procedure for the determination of glycosaminoglycan distribution patterns has been reported which is based on the sequential application of hyaluronate lyase, chrondroitinase $\mathrm{AC}$ and chondroitinase $A B C$ and high performance liquid chromatographic analysis of the products of degradation (6). This procedure has been used to identify glycosaminoglycan distribution patterns in various human connective tissues. Experience has shown that the method for the characterization of glycosaminoglycans by sequential enzymatic digestion requires verification in two respects.

Firstly, analysis of the non-sulphated glycosaminoglycan components, hyaluronate and chondroitin, has not always proved satisfactory. This has been due to inadequate precision in the determination of the non-sulphated disaccharides, due to incomplete high performance liquid chromatographic separation of accompanying substances. An improved chromatographic technique was to be used in an attempt to increase the precision of the determination of these two components.

Secondly, analysis of human hyaline cartilage by sequential glycosaminoglycan digestion surprisingly revealed dermatan sulphate in a concentration of approximately $1 \%$ of the glycosaminoglycans. To date there have been no reports of dermatan sulphate as a component of articular cartilage. However, enzymatic methods have not been used for the characterization of articular cartilage glycosaminoglycans (16). It was therefore necessary to establish whether this result could be substantiated by further analyses or whether the enzymatic method gave false results for dermatan sulphate in this concentration range.

\section{Material and Methods}

Chondroitinase $\mathrm{AC}$ (EC 4.2.2.5) and $\mathrm{ABC}$ (EC 4.2.2.4) were purchased from Miles Biochèmicals (Frankfurt, FRG) and Sigma Chemie (Munich, FRG), hyaluronate lyase (EC 4.2.99.1) from E. Merck (Darmstadt, FRG), standard disaccharides (2-acetamido-2-deoxy $=3-0-(\beta-D$-gluco-4-enepyranosyluronic acid)- $D$-galactose ( $\Delta$ DiOS), 2-acetamido-2-deoxy3-O-( $\beta$ - $D$-gluco-4-enepyranosyluronic acid)-4-O-sulpho- $D$-galactose $(\Delta \quad D i 4 S), 2$-acetamido-2-deoxy-3-O-( $\beta$ - $D$-gluco-4enepyranosyluronic acid)-6-O-sulpho- $D$-galactose ( $\Delta$ Di6S)) from Miles Biochemicals (Frankfurt, FRG). 2-Acetamido-2deoxy-3-O-( $\beta$ - $D$-gluco-4-enepyranosyluronic acid)- $D$-glucose $(\triangle \mathrm{DiHA})$ was prepared by digesting hyaluronic acid (umbilical cord, Sigma Chemie, Munich, FRG) with hyaluronate lyase followed by chondroitinase $\mathrm{AC}$, as described below. The disaccharides were isolated by precipitation of undigested material with methanol (eightfold volume), followed by chromatography on Sephacryl S 200, desalting on Sephadex G 15 and freeze-drying. All other chemicals (E. Merck, Darmstadt, FRG) were of analytical grade.

\section{Isolation of glycosaminoglycans}

The method used to isolate the glycosaminoglycans from human intervertebral discs, articular cartilage and Dupuytren's contracture has been described in full elsewhere (6). Briefly, the tissues were subjected to the following procedures: proteolysis with papain, precipitation of non-glycosaminoglycan material with perchloric acid at $\mathrm{pH} 1.3$, dialysis against double-distilled water, freeze-dyring, $\beta$-elimination in $0.3 \mathrm{~mol} / \mathrm{l} \mathrm{NaOH}$ and precipitation with ethanol (fivefold volume) after neutralization with $\mathrm{HCl}$. The resultant glycosaminoglycans were dissolved in double-distilled water and analysed by, the uronic acid assay method of Bitter \& Muir (17). 


\section{Determination of glycosaminoglycan components}

The procedure used for the analysis of glycosaminoglycan distribution patterns was based on the digestion of the polymers followed by the determination of the hydrolysis products by high performance liquid chromatography. Glycosaminoglycans corresponding to amounts of 0.5 to $1 \mu \mathrm{mol}$ uronic acid were used for each assay. The following procedures were used for enzymatic depolymerization:

\section{Digestion with hyaluronate lyase}

An aqueous solution $(500 \mu \mathrm{l})$ of glycosaminoglycans was mixed with $60 \mu \mathrm{l} 0.1 \mathrm{~mol} / 1$ sodium acetate buffer, $\mathrm{pH} 6.0$. The solution was treated for $3 \mathrm{~h}$ at $60^{\circ} \mathrm{C}$ with $20 \mu \mathrm{l}$ of a solution of hyaluronate lyase (100 turbidity-reducing units in $1 \mathrm{ml} 0.01$ mol/l sodium acetate buffer, $\mathrm{pH} 6.0$ ) followed by a second incubation step with $10 \mu$ l enzyme solution $(3 \mathrm{~h})$. The resultant oligosaccharides of hyaluronate were separated from the undigested glycosaminoglycans by precipitation with sodium acetatesaturated ethanol $(3 \mathrm{ml})$ and digested into disaccharides by chondroitinase $\mathrm{AC}$, as described below.

\section{Digestion with chondroitinase $A C$}

An aqueous solution of glycosaminoglycans $(500 \mu \mathrm{l})$ was mixed with $200 \mu \mathrm{l}$ Tris- $\mathrm{HCl}$ buffer $(0.1 \mathrm{~mol} / \mathrm{l}, \mathrm{ph} 8.0)$ and incubated for $3 \mathrm{~h}$ at $37^{\circ} \mathrm{C}$ with $20 \mu \mathrm{l}$ of a chondroitinase AC solution $(10 \mathrm{kU} / 1$ double-distilled water), followed by a second incubation with $10 \mu$ of the chondroitinase AC solution ( $3 \mathrm{~h}$, $37^{\circ}$ C).

\section{Digestion with chondroitinase $A B C$}

The digestion was performed as for chondroitinase AC except that a solution of chondroitinase $A B C(10 \mathrm{kU} / 1$ double-distilled water) was used.

Each enzymatic degradation step was followed by separation of products from the undigested glycosaminoglycans by precipitating the undigested glycosaminoglycans with $3.8 \mathrm{ml}$ sodium acetate-saturated ethanol $\left(15 \mathrm{~h}, 4^{\circ} \mathrm{C}\right)$.

The residue was washed twice with $1 \mathrm{ml}$ ethanol (volume fraction 0.96 ). The supernatants from the precipitation and the wash procedure were pooled, evaporated to dryness $\left(37^{\circ} \mathrm{C}\right)$ and dissolved in $200 \mu$ l double-distilled water. Aliquots of these solutions were analysed by high performance liquid chromatography. The following two combinations of enzymatic degradation steps were used:

\section{Method A}

Digestion with hyaluronate lyase followed by chondroitinase $A C$ and chondroitinase $A B C$.

\section{Method B}

Digestion with chondroitinase AC followed by chondroitinase $\mathrm{ABC}$.

After chondroitinase $\mathrm{ABC}$ degradation, the undigested residue was separated by thin-layer chromatography and keratan sulphate and heparan sulphate were quantified by determining hexosamine (18) and uronic acid (17) respectively, as described in a previous publication (6).

\section{High performance liquid chromatography}

The chromatograph comprised the following modules: 600/200 constant flow pump (Gynkotek, Munich, FRG), Rheodyne 7125 injection valve (Gynkotek, Munich, FRG) with a $10 \mu \mathrm{l}$ sample loop. SF 770 spectrophotometer (Kratos, Karlsruhe, FRG), an LDC 301 printer/plotter/integrator system (Milton Roy. Hasselroth, FRG) and Hyperchrome columns prepacked with Nucleosil 5 SB (Bischof Analysentechnik, Leonberg, FRG).
The columns were protected by using $20 \times 4 \mathrm{~mm}$ cartridges as precolumns, prepacked with Nucleosil 5 SB (Bischof Analysentechnik, Leonberg, FRG). The cartridges were changed after every 100 runs. The injection volume was $10 \mu l$. Elution was performed with solutions of sodium chloride filtered through a $0.4 \mu \mathrm{m}$ filter (Millipore, Neu-Isenburg, FRG) and degassed with helium. The wavelength used for detection was $230 \mathrm{~nm}$. Quantification was performed by calibration with solutions of the pure disaccharides (external standard method). All analyses were performed in duplicate. The migration of the disaccharides was characterized by the phase capacity ratio

$$
k^{\prime}=\frac{V_{R}+V_{M}}{V_{R}}
$$

(where $V_{R}=$ elution volume of the disaccharides and $V_{M}=$ elution volume of an unretained component).

Characterization of cartilage dermatan sulphate (fig. 1)

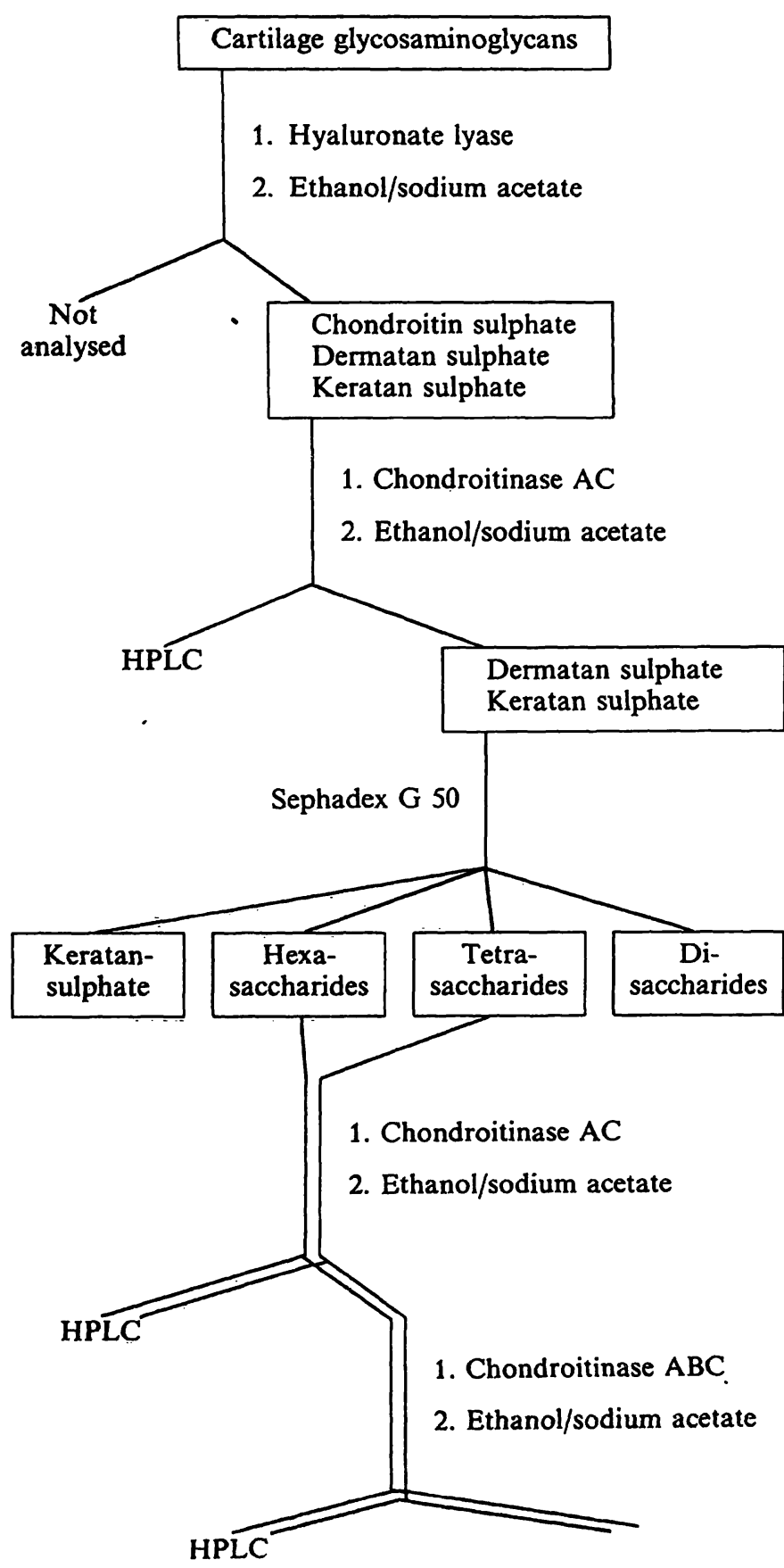

Fig. 1. Isolation and characterization of the fraction not digestable by chondroitinase AC but digestable by chondroitinase. 
Pooled glycosaminoglycans from human articular cartilage (21 to 45 years old) were digested by hyaluronate lyase and chondroitinase $A C$, as described in the previous section. The glycosaminoglycans precipitating with sodium acetate/ethanol were then chromatographed on Sephadex G $50(150 \times 0.8 \mathrm{~cm}$, $10 \mathrm{ml} / \mathrm{h}$ ) using double-distilled water as eluent. The column was characterized by chromatography of blue dextran (void volume) and the metabolites of chondroitinase AC-digested chondroitin sulphate (disaccharides) and hyaluronate lyase-digested hyaluronate (oligosaccharides). Fractions were analysed by uronic acid determination (17), hexosamine determination (18) and by absorption at $230 \mathrm{~nm}$. Peaks containing hexa- and tetrasaccharides were lyophilized, dissolved in double-distilled water and digested with chondroitinase $\mathrm{AC}$ a second time. After separation from the undigested material by ethanol/sodium acetate precipitation, the metabolites were degraded with chondroitinase $\mathrm{ABC}$. All fractions containing metabolites were evaporated, dissolved in double-distilled water and analysed by high performance liquid chromatography. At each degradation step double-distilled water was submitted to the same digestion procedure and analysed as a control.

\section{Results}

High performance liquid chromatography of the disaccharides

\section{The effect of ionic strength on the elution pattern}

Nucleosil SB is a potent ion exchanger on a silica gel basis, having a quaternary ammonium group as its functional group. Since an ion exchange mechanism may be postulated for separation, aqueous saline solutions were selected as eluents. Aqueous sodium chloride solutions, sodium sulphate solutions, buffered sodium acetate and buffered sodium phosphate solutions ( $\mathrm{pH} 4.5-6)$ were used in preliminary experiments to separate a standard solution of the pure disaccharides. The best separation results were obtained with sodium chloride solutions. All the other solutions yielded broad peaks which were not sufficiently separated in the case of the sulphated disaccharides. The addition of organic solvents (acetonitrile, methanol, tetrahydrofuran) up to volume fractions of 0.10 resulted in further peak broadening and in double peaks.

The effect of the ionic strength of the eluent on the separation pattern was studied with sodium chloride solutions in the concentration range from 0.13 to $0.25 \mathrm{~mol} / \mathrm{l}$. Chromatography was performed with a solution containing a mixture of the three pure disaccharides in concentrations of $120 \mu \mathrm{mol} / \mathrm{l}$ water.

Figure 2 shows that the phase capacity ratio $k^{\prime}$ for the two sulphated disaccharides decreases as the ionic strength increases. In this range the phase capacity ratio for the non-sulphated disaccharide displays only a slight reduction as the ionic strength increases.

Samples obtained during analysis of glycosaminoglycan distribution patterns by fractionated

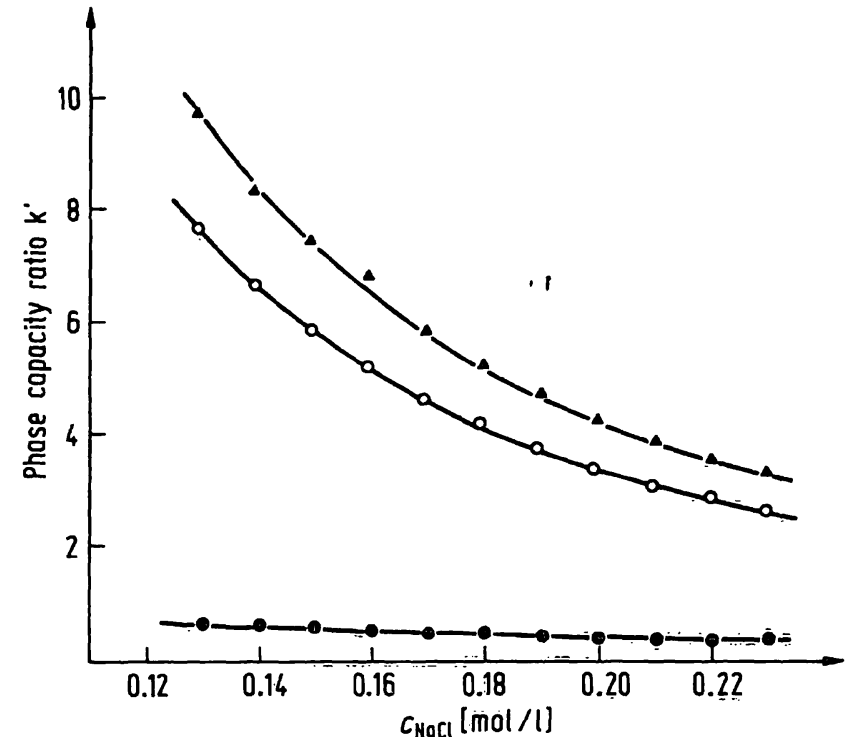

Fig. 2. Variation of the phase capacity ratio $k^{\prime}$ with ionic strength:

- 2-acetamido-2-deoxy-3-O-( $\beta$ - $D$-gluco-4-enepyranosyluronic acid)- $D$-galactose;

$\Delta$ 2-acetamido-2-deoxy-3-O-( $\beta$ - $D$-gluco-4-enepyranosyluronic acid) $4-O$-sulpho- $D$-galactose;

o 2-acetamido-2-deoxy-3-O-( $\beta$ - $D$-gluco-4-enepyranosyluronic acid)-6-O-sulpho- $D$-galactose.

Flow rate: $1 \mathrm{ml} / \mathrm{min}$.

enzymatic digestion (6) contained a number of substances (buffer salts) with retention times similar to those of the non-sulphated disaccharides. In particular, sodium acetate from the sodium acetate/ethanol precipitation step has a retention time only slightly longer than the non-sulphated disaccharides and can give rise to considerable errors due to incomplete separation. Complete separation of the non-sulphated disaccharides from the accompanying salts is achieved with eluents with sodium chloride concentrations below $0.2 \mathrm{~mol} / 1$. All chromatographic procedures wiere therefore performed using eluents containing sodium chloride in the concentration range from 0.16 to 0.18 $\mathrm{mol} / \mathrm{l}$.

\section{Linearity and reproducibility}

In order to determine the range of linearity, chromatography was performed using solutions containing mixtures of the pure disaccharides in concentrations between 10 and $4800 \mathrm{nmol} / \mathrm{ml}(0.1$ and $48 \mathrm{nmol} /$ injection). A linear increase in the signal accompanied the increase in sample concentration for the sulphated disaccharides over the entire range measured (fig. 3).

For 2-acetamido-2-deoxy-3-O-( $\beta$ - $D$-gluco-4-enepyranosyluronic acid)- $D$-galactose, the linear range only extended up to $20 \mathrm{nmol} /$ injection. Samples with a higher concentration were thereforre diluted, otherwise 


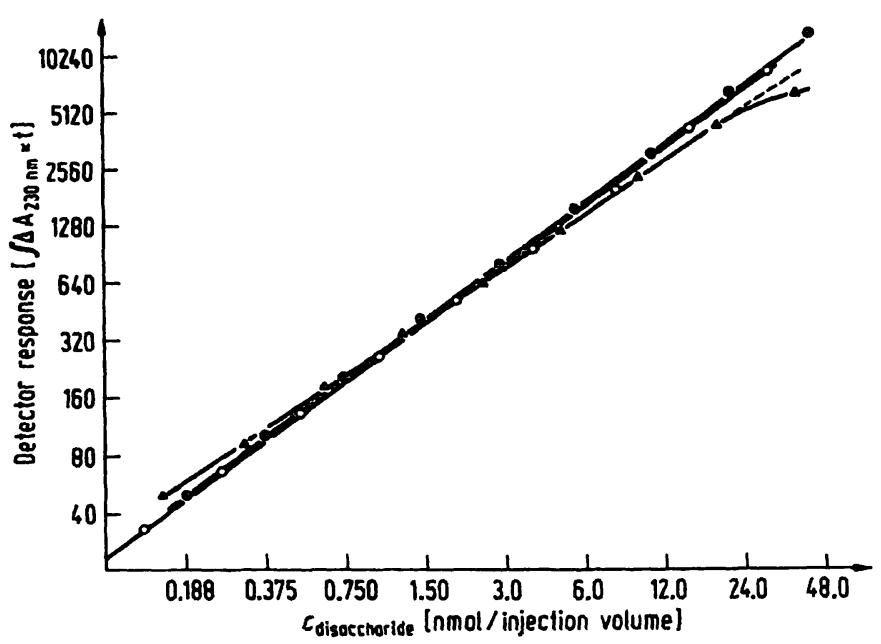

Fig. 3. Linearity of detector response: peak area vs. sample amount.

o 2-acetamido-2-deoxy-3-O-( $\beta$ - $D$-gluco-4-enepyranosyluronic acid)- $D$-galactose;

A 2-acetamido-2-deoxy-3-O-( $\beta$ - $D$-gluco-4-enepyranosyluronic acid)-4-O-sulpho- $D$-galactose;

o 2-acetamido-2-deoxy-3-O-( $\beta$ - $D$-gluco-4-enepyranosyluronic acid)-6-O-sulpho- $D$-galactose.

Flow rate: $1 \mathrm{ml} / \mathrm{min}$; eluent: $0.16 \mathrm{~mol} / 1 \mathrm{NaCl}$; column length: $4 \times 125 \mathrm{~mm}$ plus $20 \mathrm{~mm}$ precolumn.

the results obtained would have been too low. The correlation coefficients for the three disaccharides were greater than 0.998 , although for 2-acetamido-2deoxy-3-O-( $\beta$ - $D$-gluco-4-enepyranosyluronic acid)- $D$ galactose only the linear range up to $20 \mathrm{nmol}$ was taken into account.

The coefficients of variation within a series and from day to day were determined in order to monitor the reproducibility of chromatography. For this purpose a standard mixture of the three disaccharides was analysed (2-acetamido-2-deoxy-3-O-( $\beta$ - $D$-gluco4-enepyranosyluronic acid)- $D$-galactose: $130 \mu \mathrm{mol} / 1$; 2-acetamido-2-deoxy-3-O-( $\beta$ - $D$-gluco-4-enepyranosyluronic acid)-4-O-sulpho- $D$-galactose: $124 \mu \mathrm{mol} / 1$; 2-acetamido-2-deoxy-3-O-( $\beta$ - $D$-gluco-4-enepyranosyluronic acid)-6-O-sulpho- $D$-galactose: $120 \mu \mathrm{mol} / 1)$. Coefficients of variation ranging from $1.7 \%$ to $3.4 \%$ were calculated within a series of 11 chromatograms (tab. 1, I). For the determination of the coefficient of variation from day to day, 8 chromatograms were run on four consecutive days: on each of these days a standard solution was analysed at the beginning and end of a series of 45 runs. The coefficients of variation ranged between $2.0 \%$ and $3.0 \%$ (tab. 1 , II). No recalibration was carried out during this experiment but the precolumns were changed routinely after every 100 runs.

The following coefficients of variation were found for a series of 10 chromatograms for disaccharide concentrations at the lower limit of the measuring range: 2 -acetamido-2-deoxy-3-O-( $\beta$ - $D$-gluco-4-enepyranosyluronic acid)- $D$-galactose $\quad 2.9 \% \quad(19.7$ $\mu \mathrm{mol} / 1)$; 2-acetamido-2-deoxy-3-O-( $\beta$ - $D$-gluco-4-enepyra-nosyluronic acid)-4-O-sulpho- $D$-galactose $10.4 \%(21.2 \mu \mathrm{mol} / \mathrm{l})$; and 2-acetamido-2-deoxy-3-O( $\beta$ - $D$-gluco-4-enepyranosyluronic acid)-6-O-sulpho$D$-galactose $9.1 \%(18.7 \mu \mathrm{mol} / \mathrm{l})$.

\section{Separation of the non-sulphated disaccharides}

The digestion of glycosaminoglycans with chondroitinase AC yields two different non-sulphated disaccharides: 2-acetamido-2-deoxy-3-O-( $\beta$ - $D$-gluco4-enepyranosyluronic acid)- $D$-galactose from the non-sulphated regions of chondroitin sulphate and 2-acetamido-2-deoxy-3-O-( $\beta$ - $D$-gluco-4-enepyranosyluronic acid)- $D$-glucose from hyaluronate. These two disaccharides may be separated by paper chromatography. However, since this method is extremely time-consuming, an attempt was made to discover a more rapid high performance liquid chromatography method.

When the ion exchanger was used as the stationary phase, a reduction in the ionic strength of the eluent resulted in higher $\mathbf{k}^{\prime}$ values. It was therefore suspected that separation of the two sulphated disaccharides would be possible using highly dilute sodium chloride solutions as eluents. In fact, a mixture of the two

Tab. 1. Reproducibility of high performance liquid chromatographic analysis.

I: 11 runs in series;

II: 8 runs between series without recalibration (two runs each day, one at the beginning and one at the end of a series of 45 runs).

\begin{tabular}{llll}
\hline Coefficient of & 2-Acetamido-2-deoxy- & 2-Acetamido-2-deoxy- & 2-Acetamido-2-deoxy- \\
variation (\%) & 3-O-( $\beta$-D-gluco-4-ene- & 3-O-( $\beta$ - $D$-gluco-4-ene- & 3-O-( $\beta$ - $D$-gluco-4-ene- \\
& pyranosyluronic acid)- & pyranosyluronic acid)- & 6-O-sulpho- $D$-galactose \\
& $D$-galactose & 4-O-sulpho- $D$-galactose & 3.4 \\
\hline CV I & 1.7 & 2.2 & 2.0 \\
CV II & 3.0 & 2.6 &. \\
\hline
\end{tabular}


disaccharides begins to separate when salt concentrations in the eluent are below $100 \mathrm{mmol} / \mathrm{l}$. Complete baseline separation was obtained with 30 $\mathrm{mmol} / \mathrm{l}$ sodium chloride (column length: $250 \mathrm{~mm}$ ) or $15 \mathrm{mmol} / \mathrm{l}$ sodium chloride (column length $125 \mathrm{~mm}$ $+20 \mathrm{~mm}$ precolumn) (fig. 4).

Satisfactory quantitative results were obtained under these conditions even in the presence of major differences in concentration between the two nonsulphated disaccharides. Moreover, the retention times of the sulphated disaccharides were so great that they did not disturb chromatography by causing additional peaks or baseline drift within series of chromatograms.

With regard to the range of linearity, a linear increase in the signal was obtained as the sample concentration increased in the range from 14 to $3800 \mu \mathrm{mol} / \mathrm{l}(140$ pmol to $38 \mathrm{nmol} /$ injection) (fig. 5). An identical straight line was found for the two non-sulphated disaccharides. This is possibly due to the identical absorption pattern of the two disaccharides, based on a comparable steric arrangement of the $\alpha-\beta$ unsaturated carboxyl groups. The coefficients of variation within a 10 chromatogram series were $5.6 \%$ (2-acetamido-2-deoxy-3-O-( $\beta$ - $D$-gluco-4-enepyranosyluronic acid)- $D$-galactose; sample concentration: $2.38 \mathrm{nmol} /$ injection) and 3.5\% (2-acetamido-2-deoxy-

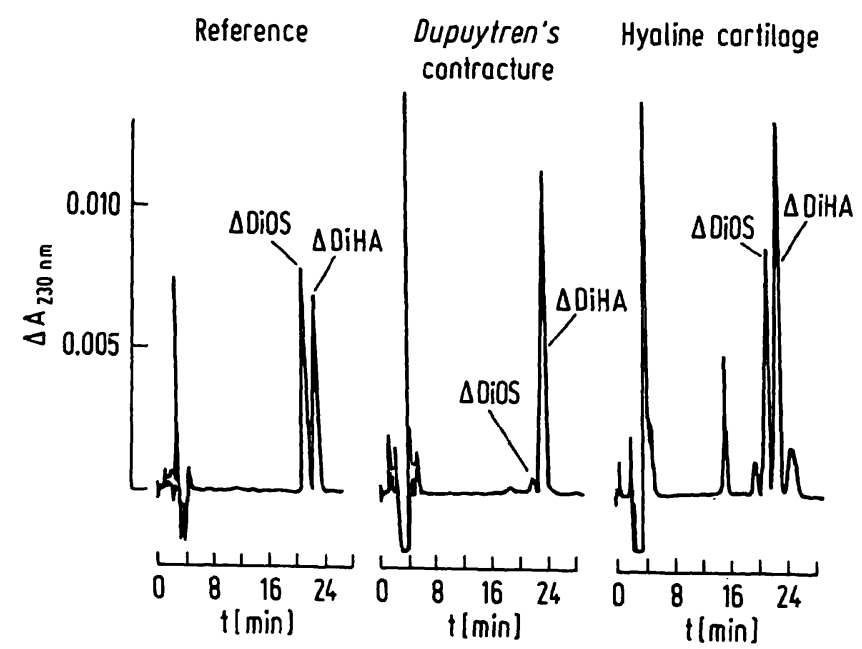

Fig. 4. Separation of non-sulphated disaccharides derived from chondroitin (2-acetamido-2-deoxy-3-O-( $\beta$ - $D$-gluco-4-enepyranosyluronic acid)- $D$-galactose, $\Delta$ DiOS) and hyaluronate (2-acetamido-2-deoxy-3-O-( $\beta$ - $D$ gluco-4-enepyranosyluronic acid)- $D$-glucose, $\triangle \mathrm{DiHA}$ ). Reference disaccharide concentrations: $\triangle$ DiOS: 233 $\mu \mathrm{mol} / \mathrm{l} ; \Delta$ DiHA: $203 \mu \mathrm{mol} / \mathrm{l}$.

Total glycosaminoglycans were isolated from $\cdot D u$ puytren's contracture and human articular cartilage. Conditions of chromatography: column lenght: $4 \times$ $250 \mathrm{~mm}$; eluent: $0.025 \mathrm{~mol} / \mathrm{l} \mathrm{NaCl}$; flow rate: $0.8 \mathrm{ml} /$ min.
3-O-( $\beta$ - $D$-gluco-4-enepyranosyluronic acid)- $D$-glucose; sample concentration: $2.10 \mathrm{nmol} /$ injection).

Dermatan sulphate in human hyaline articular cartilage

In the course of the sequential enzymatic digestion of glycosaminoglycans from human hyaline cartilage (anulus fibrosus, nucleus pulposus), a fraction was detected which was not digestable by chondroitinase $\mathrm{AC}$ but was digestable by chondroitinase $\mathrm{ABC}$ and therefore had to be designated as dermatan sulphate. Since this glycosaminoglycan component had not previously been detected in this tissue, it became necessary to verify the correctness of the enzymatic dermatan sulphate determination by further characterization of this fraction. For this purpose, hyaluronate was digested with hyaluronate lyase, then chondroitin sulphate was digested with chondroitinase AC in pooled glycosaminoglycans from human articular cartilage (fig. 1). The metabolites were separated from the undigested glycosaminoglycans by precipitation with ethanol/sodium acetate. In addition to keratan sulphate, the precipitate would have to contain the fraction which is digestable by chondroitinase $\mathrm{ABC}$ but not by chondroitinase AC. Chromatography of the precipitate on Sephadex G 50 revealed four fractions.

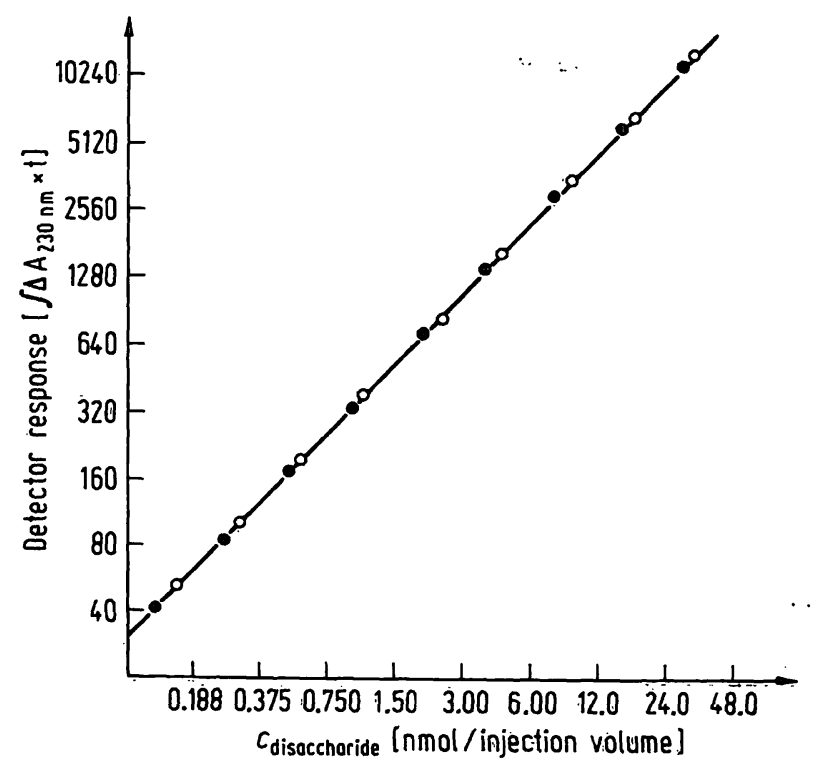

Fig. 5. Linearity of detector response: peak area vs. sample amount.

- 2-acetamido-2-deoxy-3-O-( $\beta$ - $D$-gluco-4-enepyranosyluronic acid)- $D$-galactose;

○ 2-acetamido-2-deoxy=3=O=( $\beta=D$-gluco-4-enepyranosyluronic acid)- $D$-glucose.

Flow rate: $0.8 \mathrm{ml} / \mathrm{min}$; eluent: $0.025 \mathrm{~mol} / 1 \mathrm{NaCl}$; column length: $4 \times 250 \mathrm{~mm}$. 
The fraction in the void volume contained hexosamine and no detectable quantities of uronic acids. This was therefore assigned to keratan sulphate. Uronic acids were detected by the carbazol assay in the remaining three fractions (17). In addition, like $\alpha$ - $\beta$-unsaturated uronic acids, these displayed absorption at $230 \mathrm{~nm}$. Following oligosaccharide chromatography, these three fractions were characterized as disaccharides, tetrasaccharides and hexasaccharides on the basis of their retention times.

Repeat incubation of the isolated tetra- and hexasaccharides with chondroitinase AC did not result in further cleavage of the oligomers. This demonstrated that the oligosaccharides are not susceptible to further digestion by chondroitinase AC. The activities of the enzyme solutions were verified in parallel experiments with pure chondroitin sulphates, and the absence of disaccharides in the test mixture was established with the aid of glycosaminoglycan-free blank values.

A substance which could be precipitated with ethanol/ sodium acetate could no longer be detected following incubation of the tetrasaccharides and the hexasaccharides with chondroitinase ABC. Disaccharides were obtained whose sulphation pattern differed from that of the chondroitin sulphate of this glycosaminoglycan preparation: the sulphate group was located predominantly at the $\mathrm{C}_{4}$ atom of the galactosamine. The ratio of $\mathrm{C}_{6}$ and $\mathrm{C}_{4}$ isomers was therefore far lower with the tetrasaccharides and the hexasaccharides than with the disaccharides of chondroitin sulphate (disaccharides 17; tetrasaccharides 0.25 ; hexasaccharides 0.16 ; fig. 6 ).

\section{Determination of glycosaminoglycan dis- tribution patterns}

For the determination of glycosaminoglycan distribution patterns a technique has been described in which hyaluronate, chondroitin sulphate and finally dermatan sulphate are digested in sequential steps using hyaluronate lyase, chondroitinase $\mathrm{AC}$ and chondroitinase $\mathrm{ABC}$, followed by high performance liquid chromatographic analysis of the metabolites (6). The undigested components heparan sulphate and keratan sulphate are separated by thin-layer chromatography and quantified by assaying hexosamine and uronic acid respectively. High performance liquid chromatographic separation of the non-sulphated disaccharides from hyaluronate and chondroitin should now permit the determination of these two glycosaminoglycan components directly without the use of hyaluronate lyase. Firstly, the completeness of

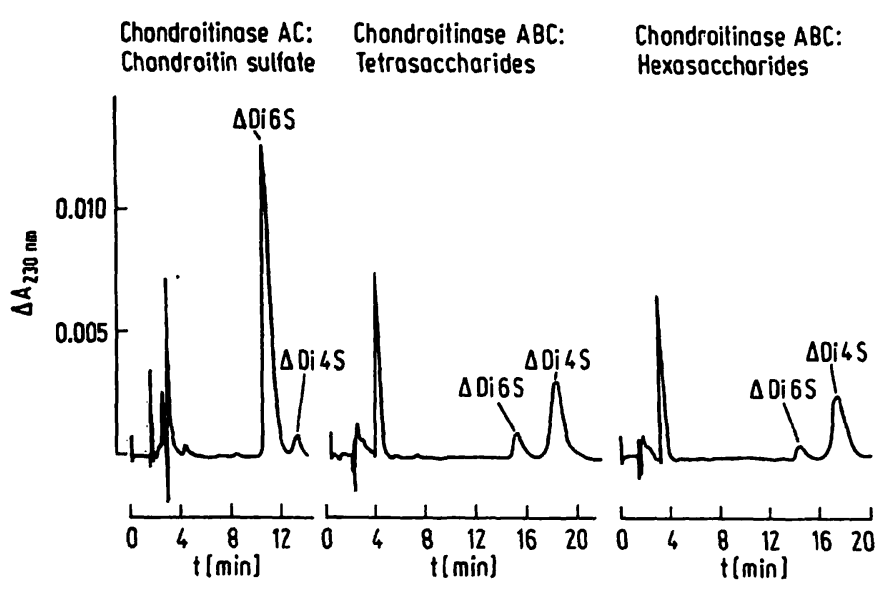

Fig. 6. High performance liquid chromatography of disaccharides from human cartilage glycosaminoglycans. Chondroitin sulphate digested by chondroitinase AC. Tetrasaccharides and hexasaccharides: fractions not digestable by chondroitinase AC but digestable by chondroitinase $\mathrm{ABC}$.

$\Delta$ Di4S: 2-acetamido-2-deoxy-3-O-( $\beta$ - $D$-gluco-4-enepyranosyluronic acid)-4-O-sulpho- $D$-galactose;

$\Delta$ DiS6: 2-acetamido-2-deoxy-3-O-( $\beta$ - $D$-gluco-4-enepyranosyluronic acid)-6-O-sulpho- $D$-galactose.

Conditions of chromatography: column length: $4 \times$ $125 \mathrm{~mm}$ plus $20 \mathrm{~mm}$ precolumn; eluent: $0.17 \mathrm{~mol} / \mathrm{l}$ $\mathrm{NaCl}$; flow rate: $1 \mathrm{ml} / \mathrm{min}$ (chondroitin sulphate) and $0.8 \mathrm{ml} / \mathrm{min}$ (oligosaccharides).

hyaluronate-chondroitin sulphate digestion by chondroitinase $\mathrm{AC}$ alone was investigated. The experiments were performed using glycosaminoglycans isolated from Dupuytren's contracture because these samples have a relatively high hyaluronate content $(22,23)$. In 5-fold determinations, digestion with chondroitinase AC was performed in two consecutive steps (I, II) to measure the completeness of the reaction. The concentration of unsaturated disāccharides was determined by high performance liquid chromatography in both fractions in exactly the same way as for the subsequent digestion step with chondroitinase $\mathrm{ABC}$.

The results (tab. 2) show that after the first digestion step with chondroitinase AC only small amounts of chondroitin and hyaluronate $(<2 \%)$ remained in the sample. Since the chondroitin sulphate metabolites were detected in approximately equal amounts, this appears to be a carry over rather than incomplete digestion due to inhibition of chondroitinase $A C$. In support of this theory, 2-acetamido-2-deoxy-3-O-( $\beta$ $D$-gluco-4-enepyranolsyluronic acid)- $D$-glucose could no longer be detected among the degradation products of chondroitinase $A B C$, even though hyaluronate is also converted to disaccharides by this enzyme, albeit more slowly than by chondroitinase AC. Hyaluronate is therefore completely digested by chondroitinase AC during the first step. The coefficients of variation 
Tab. 2. Determination of the completeness of chondroitin sulphate degradation not preceded by hyaluronate lyase application (Method B). Analysis of glycosaminoglycans isolated from Dupuytren's contracture, $\mathrm{n}=5$. Relative concentration: molar portion of total glycosaminoglycans. Digestion with chondroitinase AC was performed twice (I and II). P I: portion found in step I; P II: portion found in step II.

\begin{tabular}{llcll}
\hline $\begin{array}{l}\text { Glycosaminoglycan } \\
\text { component }\end{array}$ & $\begin{array}{l}\text { Relative } \\
\text { concentration }\end{array}$ & $\begin{array}{l}\text { Coefficient of } \\
\text { variation (\%) }\end{array}$ & P I & P II \\
\hline Hyaluronate & 0.131 & 8.4 & 0.990 & 0.010 \\
\hline Chondroitin & 0.098 & 5.9 & 0.984 & 0.016 \\
Chondroitin-4-sulphate & 0.047 & 13.4 & 0.953 & 0.047 \\
Chondroitin-6-sulphate & 0.165 & 6.8 & 0.979 & 0.021 \\
\hline Non-sulphated dermatan sulphate & 0.026 & 10.8 & - & - \\
Dermatan-4-sulphate & 0.514 & 2.5 & - & - \\
Dermatan-6-sulphate & 0.018 & 10.6 & - & - \\
\hline
\end{tabular}

ranged from $2.5 \%$ (dermatan-4-sulphate) to $13.4 \%$ (chondroitin-4-sulphate) in 5-fold determinations. The high coefficients of variation for chondroitin-4sulphate, dermatan-0-sulphate and dermatan-6sulphate may be attributed to their low concentrations. In these cases, quantities of the order of $100 \mathrm{pmol}$ had to be detected by chromatography.

In a second experiment, glycosaminoglycan analysis with the hyaluronate lyase step but without separation of the non-sulphated disaccharides (Method A) was compared for consistency with glycosaminoglycan analysis without the hyaluronate lyase step but with separation of the non-sulphated disaccharides (Method B). In this experiment, glycosaminoglycans from 4 intervertebral discs were investigated in parallel using the two methods. Table 3 shows that the results for all components were highly consistent. This also applies for the non-sulphated disaccharides when hyaluronate and chondroitin are added together.

However, lower hyaluronate and higher chondroitin concentrations were detected with Method A than with Method B. This finding is due to the formation of oligomers (tetrasaccharides, hexasaccharides and octasaccharides) from hyaluronate by hyaluronate lyase (2). The solubility of these oligosaccharides in ethanol/water solutions decreases as the proportion of ethanol and the molecular weight increase. Consequently, as the proportion of ethanol increases in the precipitation step following incubation with hyaluronate lyase, increasing amounts of hyaluronate oligosaccharides are co-precipitated with the undigested glycosaminoglycans (including chondroitin). During subsequent incubation with chondroitinase $\mathrm{AC}$, both chondroitin and the oligosaccharides are digested to form non-sulphated disaccharides. With Method A these non-sulphated disaccharides are assigned collectively to chondroitin without further differentiation by high performance liquid chro- matography. This results in excessively high chondroitin concentrations and excessively low hyaluronate concentrations. During precipitation with a 5-fold volume of ethanol after the hyaluronate lyase step, approximately $50 \%$ of hyaluronate is transferred to chondroitin (tab. 3). Following identical precipitation with a 4-fold volume of ethanol, approximately $15 \%$ of hyaluronate is transferred to chondroitin (results not shown here). In contrast, complete separation of these two components is achieved with Method B.

\section{Discussion}

High performance liquid chromatography

Descriptions of various methods for the high performance liquid chromatographic separation of $\alpha \div \beta$ unsaturated uronic acids are to be found in the published literature. However, the majority of these methods have proved unsatisfactory. Chromatography on silica gel columns is performed with a ternary elution mixture of dichloromethane, methanol and aqueous buffer solutions which is difficult to use (12). The disadvantages of ion-pair chromatography using reversed-phase columns are long retention times and pronounced sensitivity to minor variations in the eluent (13). The commonest procedure involves the use of weak anion exchangers in which primary amines form the stationary phase $(10,11)$. However, unsatisfactory results have been obtained when determining non-sulphated disaccharides from hyaluronate and chondroitin because the separation of accompanying substances is incomplete. In particular, separation of sodium acetate from the ethanol/sodium acetate precipitation step becomes less and less complete as the column becomes older, with the result that spuriously high values are obtained for 
Tab. 3. Comparison of Method A and Method B: parallel analysis of human intervertebral disc glycrsaminoglycans. Relative concentration: molar portion of total glycosaminoglycans. HA: hyaluronate; $\mathrm{Ch}$ : chondroitin; $\Sigma$ OS: hyaluronate plus chondroitin: CS4, CS6: chondroitin-4-sulphate, chondroitin-6-sulphate; DS4, DS6: dermatan-4-sulphate, dermatan-6sulphate; KS: keratan sulphate; $A_{1}, A_{2}, N_{1}, N_{2}$ : glycosaminoglycans isolated from anulus fibrosus (A) and nucleus pulposus (N) respectively.

\begin{tabular}{|c|c|c|c|c|c|c|c|c|}
\hline \multirow[t]{2}{*}{ Sample } & \multicolumn{8}{|c|}{ Relative concentration of glycosaminoglycan components } \\
\hline & HA & $\mathrm{Ch}$ & $\Sigma \mathrm{OS}$ & CS4 & CS6 & DS4 & DS6 & KS \\
\hline \multirow{6}{*}{$\begin{array}{l}A_{1} \\
A_{2} \\
N_{1} \\
N_{2}\end{array}$} & \multicolumn{8}{|c|}{ Method A (including hyaluronate lyase) } \\
\hline & 0.018 & 0.016 & 0.034 & 0.021 & 0.519 & 0.010 & 0.009 & 0.386 \\
\hline & 0.021 & 0.020 & 0.041 & 0.022 & 0.503 & 0.006 & 0.007 & 0.420 \\
\hline & 0.009 & 0.009 & 0.018 & 0.024 & 0.568 & 0.006 & 0.007 & 0.376 \\
\hline & 0.011 & 0.009 & 0.020 & 0.028 & 0.606 & 0.004 & 0.008 & 0.334 \\
\hline & \multicolumn{8}{|c|}{ Method B (excluding hyaluronate lyase) } \\
\hline $\mathbf{A}_{1}$ & 0.035 & 0.001 & 0.036 & 0.020 & 0.571 & 0.008 & 0.009 & 0.356 \\
\hline$A_{2}$ & 0.047 & 0.002 & 0.049 & 0.019 & 0.516 & 0.005 & 0.006 & 0.406 \\
\hline $\mathrm{N}_{1}^{-}$ & 0.018 & 0.002 & 0.020 & 0.023 & 0.524 & 0.003 & 0.007 & 0.424 \\
\hline $\mathrm{N}_{2}$ & 0.020 & 0.002 & 0.022 & 0.021 & 0.831 & 0.003 & 0.004 & 0.320 \\
\hline
\end{tabular}

chondroitin and hyaluronate. The use of a potent anion exchanger has been reported in the literature $(14,15)$. However, application has been limited to ${ }^{3} \mathrm{H}-$ labelled disaccharides, and quantification has been performed by fractionation and subsequent activity determination. The precision of separation, in particular that of non-sulphated disaccharides from nonlabelled buffer salts, has therefore not been assessed.

Comparison of chromatography on a potent anion exchanger with quaternary ammonium functional groups (the technique described here) and chromatography on amino phases reveals that similarly good results are obtained with both methods in the determination of the two sulphated disaccharides. However, the potent anion exchanger gives a considerably greater separation of the non-sulphated disaccharides, and separation of these disaccharides from buffer salts and other accompanying substances is complete. Consequently, compared with chromatography on $\mathrm{NH}_{2}$ phases, the determination of chondroitin and hyaluronate can be performed with greater accuracy.

In addition, 2-acetamido-2-deoxy-3-O-( $\beta$ - $D$-gluco-4enepyranosyluronic acid)- $D$-galactose and 2-acetamiido-2-deoxy-3-O-( $\beta$ - $D$-gluço-4-enepyranosyluronic acid)- $D$-glucose can be separated with a considerable reduction in the ionic strength of the eluent. It is possible to achieve baseline separation with uniform peaks. The separation of non-sulphated disaccharides on amino phases at low $\mathrm{pH}$ values has also been reported in the literature (24). However, multiple peaks (probably due to mutarotation reactions inside the separating columns) have been obtained with every substance (24). While the sep- aration performance of the high performance liquid chromatography method described in this paper is comparable with that of paper chromatography, high performance liquid chromatography is superior in terms of speed (20 minutes -28 hours) and sensitivity (detection limit: $<1 \mathrm{nmol}-20 \mathrm{nmol})(19,20)$.

In terms of practical use, the potent anion exchanger was found to be superior to the amino phase. Quantitative determination of the unsaturated disaccharides was dependent on the elution speed alone. Alterations to the sodium chloride concentration of the eluent only resulted in changes in the retention times and did not necessitate changes in the integration parameters within the studied concentration range $(0.015-0.23 \mathrm{~mol} / 1$ saline). Recalibration was therefore not required, even after column change, and regardless of the batch of stationary phase. Moreover, the life expectancy of a column was approximately 300 to 400 runs (amino phase: approximately 200 runs). However, elution speeds in excess of $1.0 \mathrm{ml} /$ min should not be used since these cause sudden breakdown of the column matrix within 50 to 100 runs.

Accuracy of the dermatan sulphate determination

It was demonstrated in a previous publication that dermatan sulphate can be accurately determined in a glycosaminoglycan pool by sequential enzymatic digestion (6). In view of the unexpected detection of small quantities of dermatan sulphate in human hyaline cartilage, it was, however, necessary to verify 
the accuracy of the method in the analysis of cartilage tissue $(6,21)$. The second incubation with chondroitinase AC showed that the oligosaccharides obtained by digestion with chondroitinase $\mathrm{AC}$ are not digestable by this enzyme even when isolated. It is therefore possible to exclude both the incomplete digestion of chondroitin sulphate by chondroitinase $\mathrm{AC}$ and the partial inhibition of chondroitinase AC by other substances during the first incubation step. However, the oligosaccharides are cleaved by chondroitinase $\mathrm{ABC}$ to form disaccharides. In contrast to chondroitinase $A C$, chondroitinase $A B C$ cleaves the bonds between galactosamine and iduronic acid. It may therefore be assumed that iduronic acid is present in the oligosaccharides, even though the lack of a sufficiently sensitive assay method for such small quantities has meant that it could not be detected.

Characterization of the fractions not digestable by chondroitinase AC but completely digestable by chondroitinase $A B C$ has revealed that the sulphation pattern deviates markedly from that of chondroitin sulphate: the galactosamine is sulphated predominantly at $\mathrm{C}_{4}$, with the result that the ratio of $\mathrm{C}_{6}$ and $\mathrm{C}_{4}$ isomers is about 100 times lower than with chondroitin sulphate. Comparable differences were also discovered during the determination of glycosaminoglycan distribution patterns of intervertebral discs (25). Dermatan sulphate is reported also to be sulphated predominantly at the $\mathrm{C}_{4}$ atom of galactosamine $(16,26,27)$. Given the specificity of the digesting enzymes and the high proportion of 4sulphated galactosamines, it may therefore be assumed that the cartilage fraction studied here differs from chondroitin sulphate and should presumably be assigned to dermatan sulphate.

The occurrence of oligosaccharides following digestion with chondroitinase AC suggests that this dermatan sulphate of articular cartilage forms hybrid molecules with chondroitin sulphate, a phenomenon which has been reported for other tissues (27). It is not known whether the dermatan sulphate regions are components of a few glycosaminoglycan chains or whether they are distributed throughout the entire chondroitin sulphate-containing region of the proteoglycans. If it is assumed that the iduronic acid components are distributed more or less uniformly throughout the chondroitin sulphate-containing region, then because of their small number, they will exert non influence on the overall physico-chemical behaviour of these chains. This would explain why dermatan sulphate has not been detected in articular cartilage by physicochemical methods.
Chondroitin/hyaluronate determination during glycosaminoglycan analysis

In Method A, which involves the hyaluronate lyase step for the analysis of glycosaminoglycan distribution patterns, hyaluronate and chondroitin are separated by the enzymatic digestion of hyaluronate with hyaluronate lyase, and the hyaluronate oligomers are then separated from the chondroitin-containing undigested glycosaminoglycans by the ethanol/ sodium acetate precipitation step. The two components are quantified by the high performance liquid chromatographic determination of the nonsulphated disaccharides in the corresponding fractions. The quality of the separation of hyaluronate oligomers and undigested glycosaminoglycans is critical for accuracy. Complete separation is possible by gel chromatography (20) but this method is too laborious for the analysis of relatively large sample series. Separation by ethanol/sodium acetate precipitation is simpler but has been found to be incomplete because more and more hyaluronate oligomers are co-precipitated as the ethanol content increases.

The use of high performance liquid chromatography to separate the non-sulphated disaccharides within the previously described analytical procedure eliminates the differentiation of chondroitin and hyaluronate by the hyaluronate lyase step, because 2-acetamido-2-deoxy-3-O-( $\beta$ - $D$-gluco-4-enepyranosyluronic acid)- $D$-glucose and 2-acetamido-2-deoxy3-O-( $\beta$ - $D$-gluco-4-enepyranosyluronic acid)- $D$-galactose can be determined simultaneously and unequivocally as degradation products of chondroitinase AC.

The direct identification of hyaluronate and chondroitin as degradation products of chondroitinase $\mathrm{AC}$ is thus a major improvement in the enzymatic characterization of glycosaminoglycans. The high performance liquid chromatographic separation of the two non-sulphated disaccharides permits greater accuracy in the determination of hyaluronate and chondroitin. Due to the elimination of the hyaluronate lyase step from the analytical procedure, the method not only becomes simpler but also yields a superior result.

\section{Acknowledgement}

This, work was supported by the Deutsche Forschungsgemeinschaft (SFB 54) and contains sections of the dissertations by $G$. Pallasch and S. Tunn. 


\section{References}

1. Saito, H., Yamagata, T. \& Suzuki, S. (1968) J. Biol. Chem. 243. $1536-1542$.

2. Ohya, T. \& Kaneko, K. (1970) Biochim. Biophys. Acta 198, 607-609.

3. Murata, K. \& Bjelle, A. O. (1980) Conn. Tiss. Res. 7, 143-156.

4. Capeletti, R., Del Rosso, M. \& Chiarugi, V. (1980) Anal. Biochem. 105, 430-435.

5. Breen, M., Knepper, P. A., Weinstein, H. G., Black, L. J., Lewandowski, D. L. \& Baltrus, B. M. (1981) Anal. Biochem. $113,416-422$.

6. Gurr, E., Schubert, R., Delbrück, A. \& Köller, W. (1982) J. Clin. Chem. Clin. Biochem. 20, 723-729.

7. Gressner, A. M., Scherer, R. R., Stuhlsatz, H. W. \& Greiling, H. (1981) J. Clin. Chem. Clin. Biochem. 19, 221-222.

8. Yamagata, T., Saito, H., Habuchi, O. \& Suzuki, S. (1968) J. Biol. Chem. 243, 1523-1535.

9. Wassermann, L., Ber, A. \& Allalouf, D. (1977) J. Chromatogr. 136, 342-347.

10. Lee, G.J. \& Tieckelmann, H. (1979) Anal. Biochem. 94, $231-236$

11. Hjerpe, A., Antonoloulos, C.A. \& Engfeld, B. (1979) J. Chromatogr. 171, 339-344.

12. Lee, G.J., Evans, J.E. \& Tieckelmann, H. (1979) J. Chromatogr. 146, 439-448.

13. Otani, N., Sato, N. \& Yosizawa, Z. (1979) J. Biochem. (Tokyo) 85, 1383-1385.
14. Delaney, S. R., Leger, M. \& Conrad, H.E. (1980) Anal. Biochem. 106, 253-261.

15. Delaney, S. R., Conrad, H. E. \& Glaser, J.H. (1980) Anal. Biochem. 108, 25-34.

16. Rodén, L. (1980) In: The Biochemistry of Glycoproteins and Proteoglycans (Lennarz, W.J., ed.) pp. 352-371. Plenum Press, New York.

17. Bitter, A. \& Muir, H. (1982) Anal. Biochem. 4, 330-334.

18. Blumenkranz, N. \& Asboe-Hansen, G. (1976) Clin. Biochem. 9, 269-274.

19. Murata, K. (1980) Biochem. Med. 23, 324-325.

20. Kleine, T. O. \& Merten, B. (1981) Anal. Biochem. 118, $185-190$.

21. Gurr, E., Kellner, C. \& Delbrück, A. VIIIth meeting of the Federation of European Connective Tissue Societies, Copenhagen (1982) p. 111.

22. Berger, A. \& Gurr. E. Handchirurgie, in press.

23. Flint, M.H., Gillard, G. C. \& Reilly, H.C. (1982) Conn. Tiss. Res. 9, 173-179.

24. Hjerpe, A., Antonopoulos, C. A. \& Engfeldt, B. (1982) J. Chromatogr. 245, 365-368.

25. Gurr, E. \& Köller, W. unpublished result.

26. Fransson, L. A. (1968) Biol. Chem. 243, 1504-1510.

27. Fransson, L. A. (1968) Archiv for Kemi 29, 95-98.

28. Stuhlsatz, H. W. \& Greiling, H. (1976) In: The Methodology of Connective Tissue Research (Hall, D.A., ed.) pp. 129-136, Joynson-Bruvvers Ltd., Oxford.

Dr. Eberhard Gurr Institut f. Klin. Chemie II der Medizinischen Hochschule Hannover Podbielskistraße 380

D-3000 Hannover 51 
I 